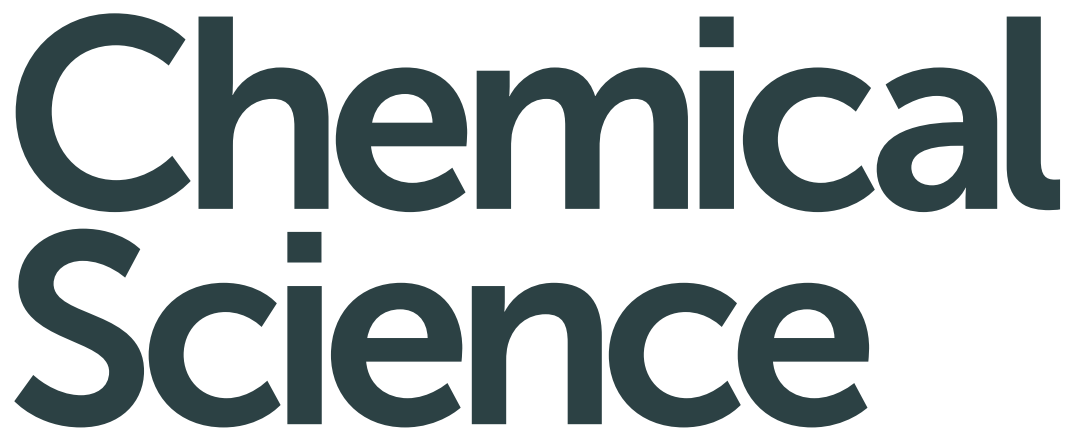

www.rsc.org/chemicalscience

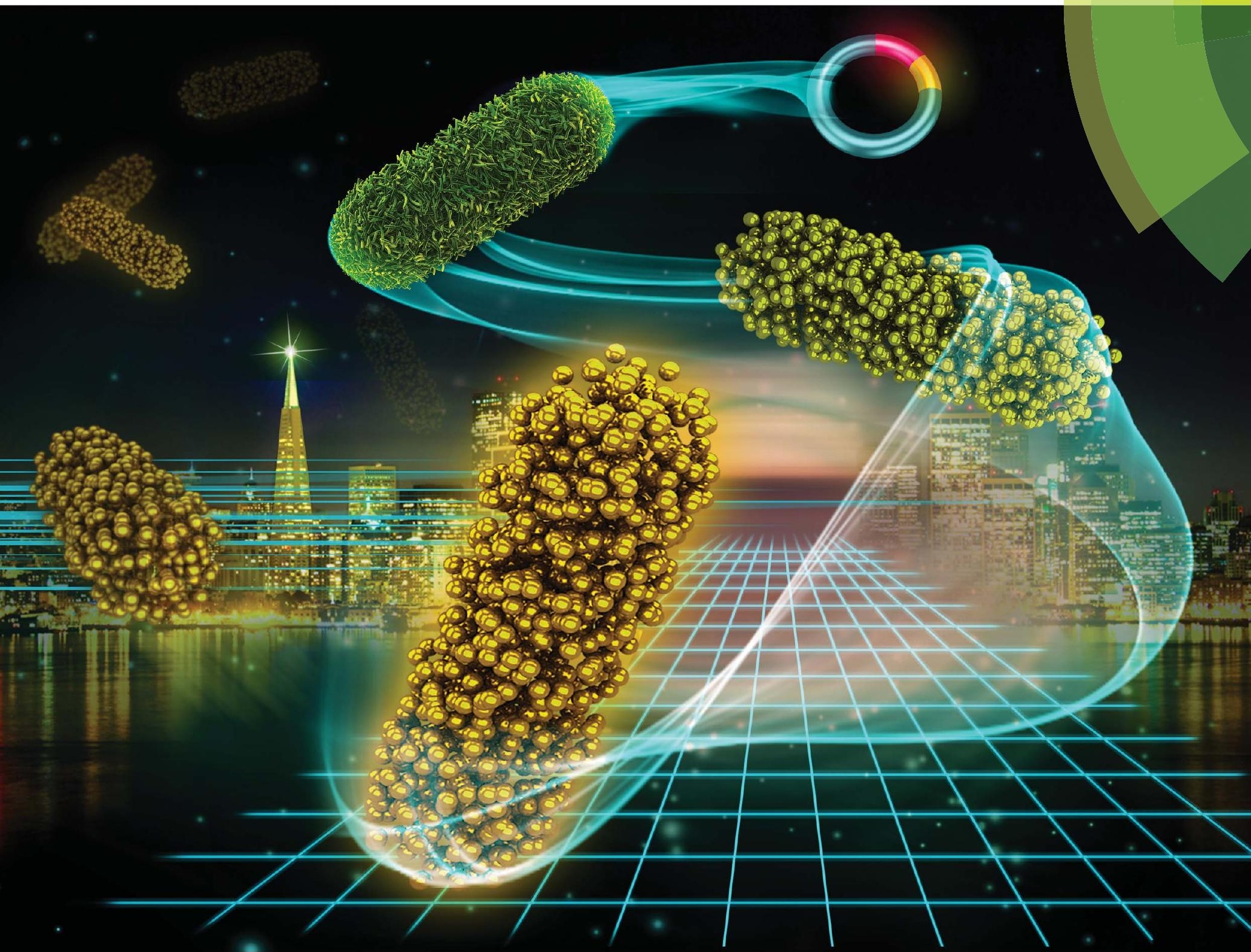

ISSN 2041-6539

12

ROYAL SOCIETY OF CHEMISTRY
EDGE ARTICLE

Hao Xie, Zhengyi Fu et al.

Confined-space synthesis of nanostructured anatase, directed by

genetically engineered living organisms for lithium-ion batteries 


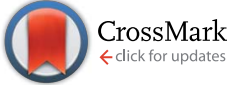

Cite this: Chem. Sci., 2016, 7, 6330

\title{
Confined-space synthesis of nanostructured anatase, directed by genetically engineered living organisms for lithium-ion batteries $\dagger$
}

\author{
Hang Ping, ${ }^{a}$ Hao Xie, ${ }^{\text {tb }}$ Mingyu Xiang, ${ }^{a}$ Bao-Lian Su, ${ }^{c}$ Yucheng Wang, ${ }^{a}$ \\ Jinyong Zhang, ${ }^{a}$ Fan Zhang $^{a}$ and Zhengyi Fu*a
}

Biomineral formation processes in nature are temporally and spatially regulated under the functions of biomolecules in a confined space. It is potentially very productive to rationally design a mineralized system by taking into account confined space as well as biomolecules. The laboratory technique of "bacterial cell surface display" is an ideal platform to host catalytically active proteins in a threedimensionally confined space. In the present study, aiming to regulate the synthesis of nanostructured $\mathrm{TiO}_{2}$ anatase, repeating segments of silaffin were displayed on Escherichia coli surfaces through genetic manipulation. The displayed protein electrostatically interacted with a titanium source and catalyzed the hydrolysis of titanium dioxide precursors through hydrogen bonding interactions on the cell surface. In the subsequent calcination process, the genetically modified cells not only served as a framework for producing rod-shaped $\mathrm{TiO}_{2}$ assembled by nanoparticles, but also provided a carbon source in situ. The size of nanoparticles was controlled by changing the number of tandem repeats of the protein segment. The as prepared $\mathrm{TiO}_{2}$ anatase exhibited unique characteristics including nanosized anatase crystals, mesoporous structure and carbon coating. When tested as the anode electrode of a lithium-ion battery, it showed excellent lithium storage performance. The carbon coated anatase anode shows a higher specific capacity of $207 \mathrm{~mA} \mathrm{~h} \mathrm{~g}{ }^{-1}$ after 200 cycles at a current rate of $1 \mathrm{C}$ and an ultra-long cycling lifetime of 5000 cycles with an outstanding retention capacity of $149 \mathrm{~mA} \mathrm{~h} \mathrm{~g}^{-1}$ at a higher rate of $10 \mathrm{C}$.

This bioprocess-inspired approach may help broaden the scope and impact of nanosized biominerals.

Received 24th May 2016

Accepted 14th July 2016

DOI: $10.1039 / \mathrm{c} 6 \mathrm{sc0} 0231 \mathrm{~h}$

www.rsc.org/chemicalscience

\section{Introduction}

Over billions of years of evolution, living organisms have become very efficient at synthesizing biominerals with exquisite morphology and hierarchical structure. ${ }^{1}$ The amazing structureformation processes for biominerals can inspire a wide range of advanced techniques for fabricating new materials. Learning from the biomineral-forming process, the concept of "bioprocess-inspired fabrication" has been put forward., ${ }^{2,3}$ The natural process of biomineral formation is temporally and spatially regulated under the functions of biomolecules in a confined space. ${ }^{4}$ It is believed that soluble proteins determine the morphology, orientation and polymorph type of a biomineral within a confined space. ${ }^{5,6}$ Biomolecules and confined

\footnotetext{
${ }^{a}$ State Key Laboratory of Advanced Technology for Materials Synthesis and Processing, Wuhan University of Technology, Wuhan, 430070, China. E-mail: zyfu@whut.edu.cn ${ }^{b}$ School of Chemistry, Chemical Engineering, and Life Science, Wuhan University of Technology, Wuhan, 430070, China. E-mail: h.xie@whut.edu.cn

'Laboratory of Inorganic Materials Chemistry, University of Namur, Namur, B-500o, Belgium
}

$\dagger$ Electronic supplementary information (ESI) available. See DOI: $10.1039 / \mathrm{c} 6 \mathrm{sc} 02311 \mathrm{~h}$ space are the two indispensable factors and play complementary roles in the elaborate structure and morphology of biominerals. But, only considering biomolecules may lead to low controllability of size and structure of products in vitro. ${ }^{7,8}$ Similarly, taking advantage of only artificially confined space may yield products with erratic composition and morphology. ${ }^{9,10}$ Therefore, in order to investigate the natural formation process deeply, it is necessary to choose an appropriate system that combines the two factors to direct the synthesis of materials. ${ }^{11-16}$

The cell surface display technique allows the expression of desired proteins on the cell surface, which provides an ideal platform for biomolecules in a confined space. Genetically engineered cell surfaces with displayed mineral proteins can direct the growth of minerals under a range of controlled temporal and spatial variations. Furthermore, they permit a wider selection of proteins to be employed in synthesizing materials and precisely controlling size distribution through protein modification. ${ }^{17}$ An amyloid or M13 virus serves as an integrated biomolecule in a one-dimensionally confined space to induce the synthesis of wire-shaped minerals. ${ }^{11-14}$ Twodimensional confined systems have been established by depositing the biomolecules on a proper matrix to control the 
monodispersity of nanoparticles. ${ }^{15,16}$ For mineralization in a one- or two-dimensionally confined space, it is not easy to realize and tune the exquisite structures that are found in biominerals. Since the cell surface supports a three-dimensionally confined space, it can be applied to synthesize materials with a three-dimensional architecture composed of nanoparticles. To date, relevant work is very limited, and the composition and structure of products both need further study. ${ }^{18-20}$

The present study aims to explore a cell surface capable of displaying a catalytically active protein to direct the synthesis of nanostructured anatase $\mathrm{TiO}_{2}$ in a three-dimensionally confined space. Titanium dioxide is one of the widely studied materials, due to its numerous potential applications, including energy conversion and storage. ${ }^{21-24}$ To improve a sample's lithium storage capacity, possible solutions are devoted to reducing particle size and adding conductive carbon, which can efficiently shorten the Li-ion diffusion pathway and enhance electron conductivity respectively. ${ }^{25,26}$ We propose that genetically engineered cells will not only serve as a framework to fabricate rod-shaped $\mathrm{TiO}_{2}$ assembled by nanoparticles, but also provide a carbon source to uniformly coat carbon onto the exposed surfaces of nanoparticles. The nanostructured anatase anode, as an anode material for lithium-ion batteries, exhibits excellent specific capacity, rate capability and ultra-long cycling lifetime.

\section{Results and discussion}

\section{Biological activity of recombinant protein on the surface of $E$. coli}

In consideration of cytocompatibility and mineral-formation activities, ${ }^{8,27}$ three artificial proteins $n \mathrm{R} 5(n=1,3,5)$, containing different numbers of repeating segments of R5, were chosen and displayed on the surface of Escherichia coli (E. coli). Peptide $\mathrm{R} 5$ is the building block of silaffin and can efficiently induce the formation of $\mathrm{TiO}_{2} \cdot{ }^{8}$ The artificial protein $n \mathrm{R} 5$ was genetically inserted downstream of an ice nucleation protein (INP) that served as an anchor for $n$ R5 on the E. coli surface (Fig. 1a). INP is an efficient and stable carrier protein, which can transport a fused protein through the complex cell envelope structure and is resistant to attack or detachment. ${ }^{28}$ The expression and size of INP-fused $n$ R5 (INP- $n$ R5) was determined through gel electrophoresis analysis (Fig. S1 $\dagger$ ). Exclusive display of INP- $n$ R5 was observed in the outer membrane of E. coli.

Interactions between the genetically engineered bacterial surface and the titanium source solution were investigated by electron microscopy. When titanium(Iv)bis(ammonium lactato) dihydroxide solution (TiBALDH) was mixed with INP-modified E. coli cells at $37{ }^{\circ} \mathrm{C}$, smooth cell surfaces were observed (Fig. S2a $\dagger$ ). When TiBALDH solution was mixed with $E$. coli cells with INP-5R5 on the surface at $37^{\circ} \mathrm{C}$, there was a significant change in the surface roughness of INP-5R5 modified E. coli, implying the deposition of titanium dioxide precursors on the cell surface (Fig. 1b and S2b†). Microtome TEM images clearly display the deposition of precursor under the function of 5R5 (Fig. 1c). Since 5R5 has a high positive charge due to the lysine richness of its sequence, ${ }^{7}$ it facilitates the interaction between the cell surface and a negatively charged titanium source, which
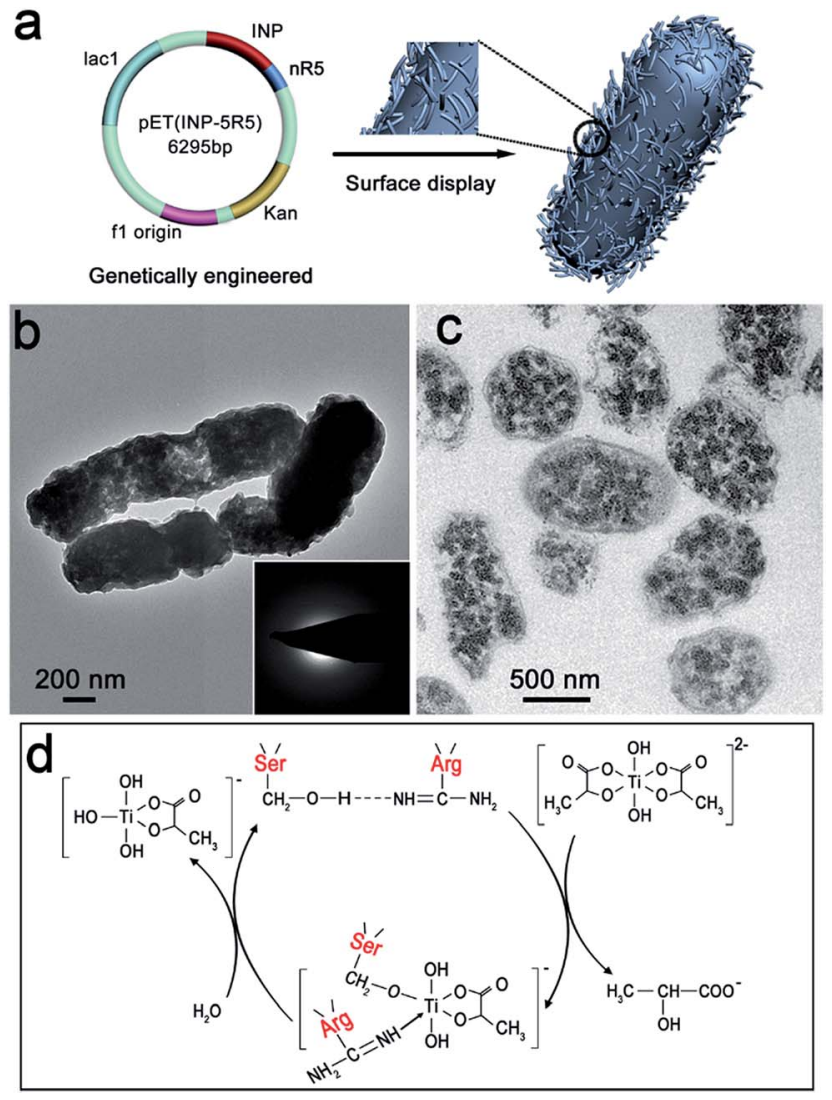

Fig. 1 Mineralization on the surface of genetically engineered bacteria. (a) Schematic of the cell surface display technique. (b) TEM image and corresponding SAED (inset) and (c) microtome TEM image of mineralized IPTG-induced INP-5R5 cells. (d) Proposed reaction mechanism of the catalysis of TiBALDH hydrolysis.

results in accumulation of precursor particles on the cell surface. The amorphous nature of precursor particles was revealed by selected area electron diffraction (SAED) (Fig. 1b insets) and X-ray diffraction (XRD) (Fig. S2g†).

After continuously incubating the products at $80{ }^{\circ} \mathrm{C}$, INPmodified cells displayed smooth surfaces (Fig. S2c and eiं), whereas more curved and rougher surfaces were obtained for 5R5-modified cells (Fig. S2d and f†). A high-magnification image shows nanoparticles on the surface. The weak and broad peak at $26^{\circ}$ implies the existence of anatase crystal nuclei (Fig. S2h $\dagger$ ), which benefit from the enzymatically catalytic activity of 5R5, containing many serine (Ser) and arginine (Arg) amino acids (Fig. S3†).

Hydrogen bonding occurred between the hydroxyl group of serine (Ser) and the imino group nitrogen of arginine (Arg) at the carbonyl carbon (Fig. 1d), which increased the nucleophilicity of the hydroxyl oxygen. This facilitated nucleophilic attack on the substrate titanium center, leading to hydrolysis and condensation..$^{7,29,30}$ Nucleophilic attack was followed by elimination of 2-hydroxy propionic acid and the formation of a Ser$\mathrm{O}-\mathrm{Ti}$ intermediate, and nitrogen donation from Arg potentially stabilized the intermediate. The reaction between the intermediate and water led to the formation of Ti-OH bonding via hydrolysis. Finally, condensation occurred between Ti-OH 
bonds, which formed the titanium dioxide framework, and the anatase nuclei appeared after incubation at $80{ }^{\circ} \mathrm{C}$.

\section{Synthesis of nanostructured anatase with controlled size}

The rod-shaped structure of the precursor coated cells was retained with slight shrinkage after calcination at $600{ }^{\circ} \mathrm{C}$ for $4 \mathrm{~h}$ in air (denoted as 5- $\mathrm{TiO}_{2}$ ). The $E$. coli cells served as a framework or template for formation of rod-shaped $\mathrm{TiO}_{2}$ (Fig. 2a and $\mathrm{S} 4 \mathrm{a} \dagger$ ). Nanoparticles with an average size of $5 \mathrm{~nm}$ are clearly observed through the tip of a representative broken rod (Fig. 2b). Polycrystallinity of the rod-shaped structure was confirmed by SAED (Fig. 2a inset). The crystallographic phase was indexed to anatase $\mathrm{TiO}_{2}$ (JCPDS no. 21-1271) by XRD analysis (Fig. 2e), and the interplanar spacing of $0.35 \mathrm{~nm}$ was assigned to the (101) plane of anatase (Fig. 2b). However, when INP-modified cells were subjected to calcination, tetragonal particles aggregated together, and the rod-shaped structure of the bacteria collapsed (Fig. S4b $\dagger$ ).

A nitrogen adsorption-desorption isotherm (IV type) indicates products with mesoporous structures and pore sizes
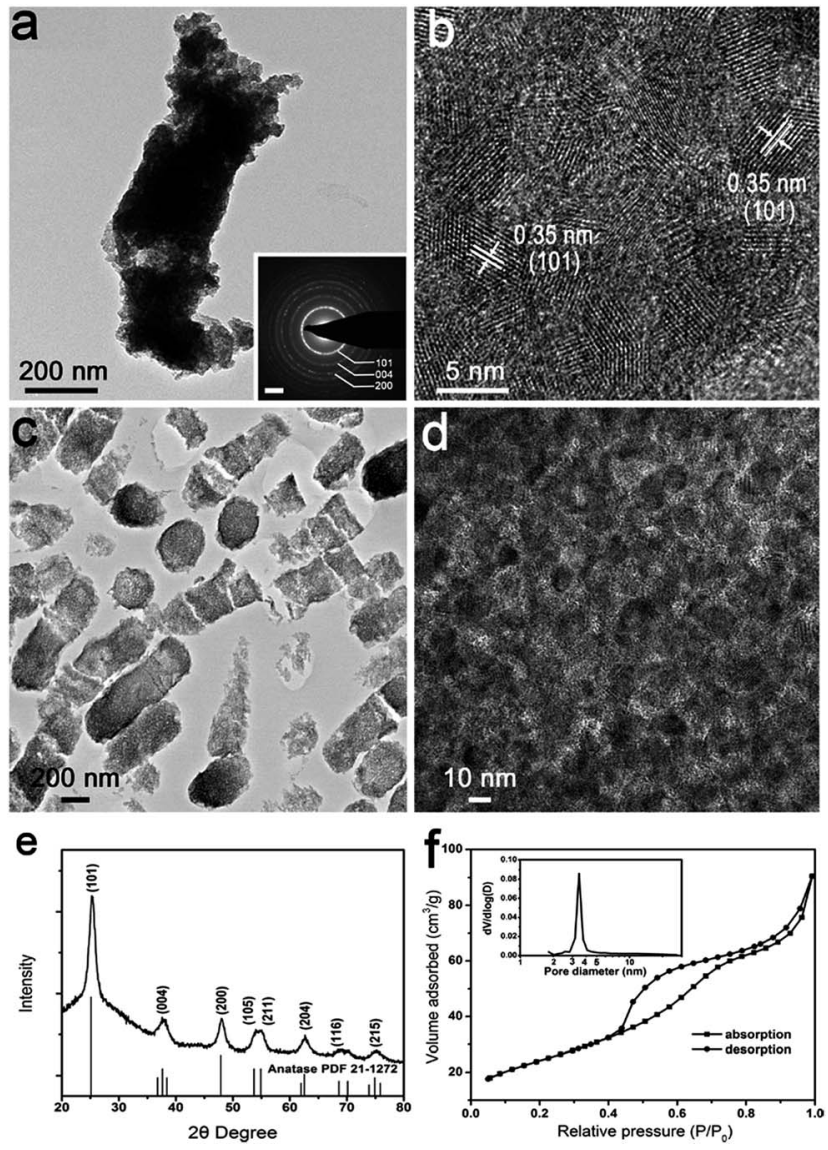

Fig. 2 Characterization of nanostructured anatase $5-\mathrm{TiO}_{2}$ annealed under air. (a) TEM image and corresponding SAED (inset) of representative rod-shaped structure. Scale bar in the inset is $2 \mathrm{~nm}^{-1}$. (b) HRTEM image of the rod-shaped structure. (c) Low and (d) high magnification microtome TEM images of anatase. (e) XRD pattern of nanostructured anatase. (f) Nitrogen adsorption and desorption isotherms and pore size distribution (inset). mainly in the range of 3-4 $\mathrm{nm}$ (Fig. 2f inset). The specific surface area and pore volume were determined to be $87.8 \mathrm{~m}^{2}$ $\mathrm{g}^{-1}$ and $0.14 \mathrm{~cm}^{3} \mathrm{~g}^{-1}$, respectively (Fig. 2f). In order to observe the internal structure of the rod-shaped $\mathrm{TiO}_{2}$, ultramicrotomy was employed to cut specimens into ultra-thin sections (about $100 \mathrm{~nm}$ ). The longitudinal and transverse sections of $\mathrm{TiO}_{2}$ were distinctly identified from a microtome TEM image (Fig. 2c). The central region of a transverse section exhibits a coherent mesoporous structure. The gap size between nanoparticles corresponds to the results of pore-distribution analysis (Fig. 2d).

Surface-displayed protein $5 \mathrm{R} 5$ plays an important role in the formation of $5 \mathrm{~nm}$ anatase nanoparticles. Because cationic 5R5 may accumulate and hydrolyse oppositely charged TiBALDH molecules, the products of hydrolysis deposited around the protein domain and then were wrapped by proteins. The growth and aggregation of titanium dioxide nanoparticles could been prohibited by the entangled protein network..$^{15,31,32}$ When the number of tandem repeats of 5R5 was reduced, the entangled network effect was weakened, resulting in increased particle size. In each sample, R5 segments with a particular number of repeated units (R5, 3R5 and 5R5) were displayed on the surface of $E$. coli. Hence, the anatase phase was obtained with the same number of R5 repeating segments (Fig. S5a $\dagger$ ). However, the rodshaped structure was assembled of nanoparticles of different sizes (denoted as $1-\mathrm{TiO}_{2}$ and $3-\mathrm{TiO}_{2}$, respectively) (Fig. 3). The particle size was slightly larger when the number of repeated R5 segments was lower. The specific surface areas of $1-\mathrm{TiO}_{2}, 3-\mathrm{TiO}_{2}$ and $5-\mathrm{TiO}_{2}$ were determined to be $56.2,78.5$ and $87.8 \mathrm{~m}^{2} \mathrm{~g}^{-1}$, respectively (Fig. S5b广).

\section{Synthesis of carbon coated nanostructured anatase}

In our system, the bacteria both served as a confining framework and provided an in situ carbon source during calcination

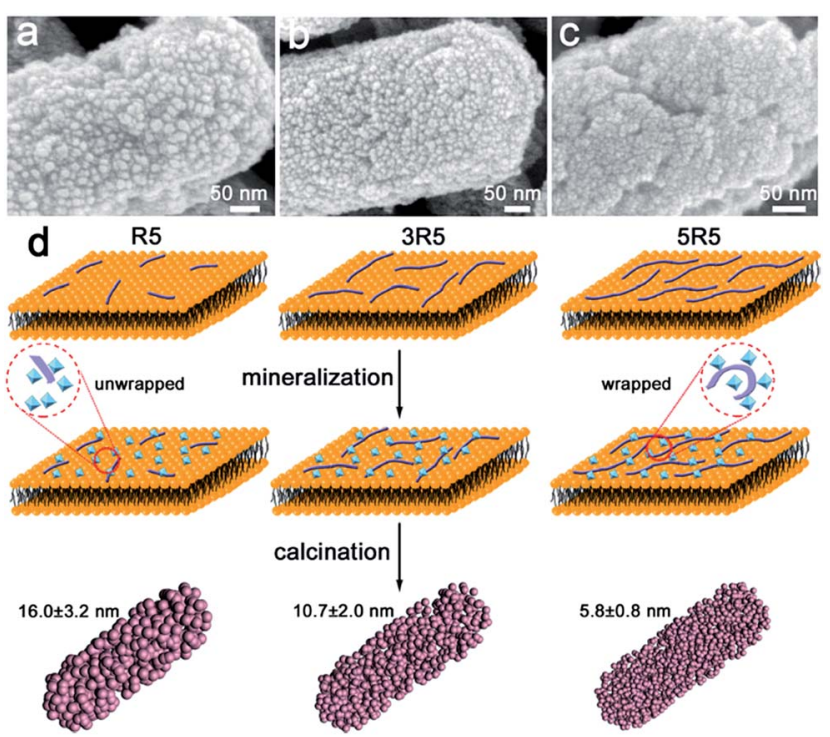

Fig. 3 Characterization of size-tunable anatase $n-\mathrm{TiO}_{2}(n=1,3,5)$. SEM images of (a) $1-\mathrm{TiO}_{2}$, (b) $3-\mathrm{TiO}_{2}$, (c) $5-\mathrm{TiO}_{2}$. (d) Schematic of confined space mineralization controlled by the number of repeating segments of R5. 
to avoid joining a second phase. ${ }^{33}$ When annealing was done at $600{ }^{\circ} \mathrm{C}$ for $4 \mathrm{~h}$ in $\mathrm{Ar}$, the same anatase phase was obtained (denoted as carbon coated $\mathrm{TiO}_{2}\left(5-\mathrm{TiO}_{2} / \mathrm{C}\right)$ ) (Fig. S6 $\dagger$ ). There was no significant difference between heating treatment in air and $\mathrm{Ar}$, in terms of morphology and particle size of anatase (Fig. S7†). In particular, the particle size of the exterior structure in $5-\mathrm{TiO}_{2} / \mathrm{C}$ is the same as that of the interior. Fig. 4a shows a TEM image of a representative carbon coated rod-shaped structure, which is about $300 \mathrm{~nm}$ in diameter and $1 \mu \mathrm{m}$ in length. The SAED pattern also indicates the polycrystalline nature of the products (Fig. 4a inset). As evident in Fig. 4b, a carbon layer, 1-2 nm thick, uniformly coats the surface of the nanoparticles. Energy-dispersive spectroscopy (EDS) elemental mapping images also confirm the uniform distribution of Ti, $\mathrm{O}$ and $\mathrm{C}$ (Fig. S8 $\dagger$ ). The cross-sectional TEM image of $5-\mathrm{TiO}_{2} / \mathrm{C}$ also shows the evident mesoporous structure after carbonization (Fig. 4c). To explore the behavior of carbon coating in the interior structure, a high magnification TEM image of the central area in Fig. 4c reveals that there is amorphous carbon coating on the exposed surface of the nanoparticles (Fig. 4d).
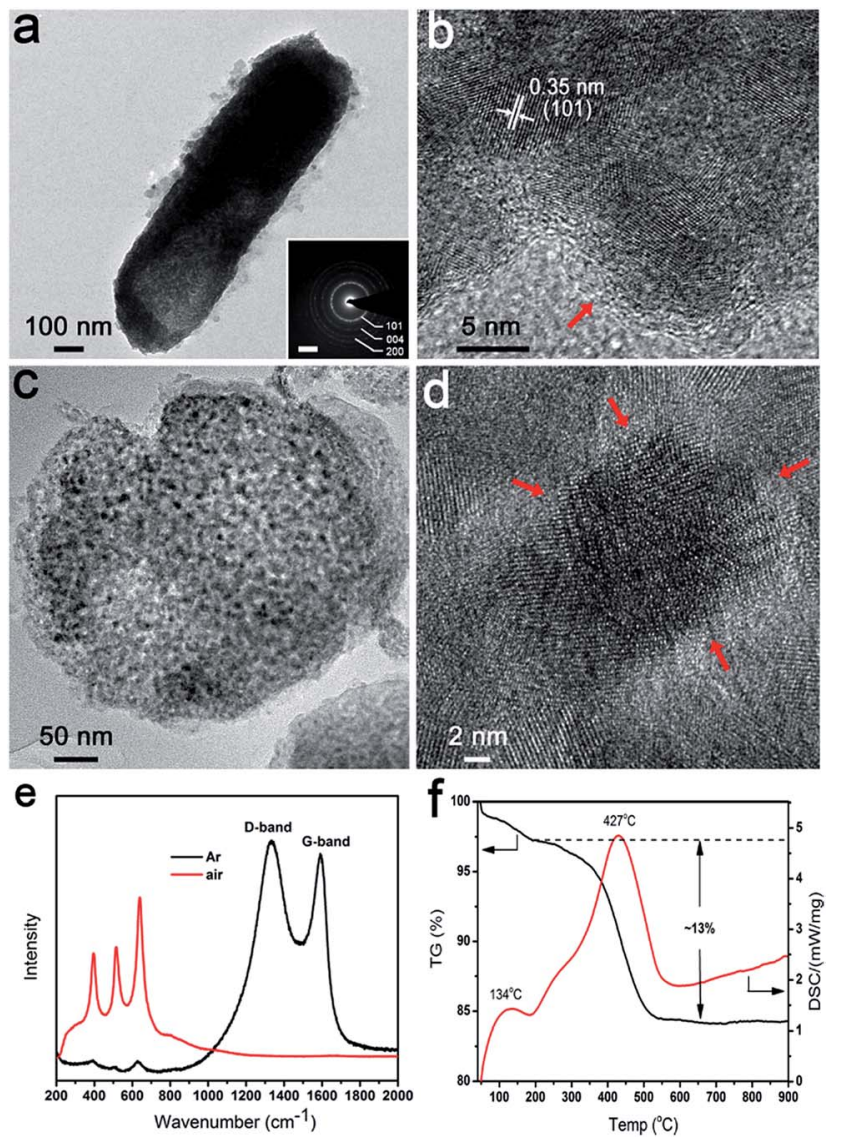

Fig. 4 Characterization of nanostructured anatase $5-\mathrm{TiO}_{2} / \mathrm{C}$ annealed under inert Ar. (a) TEM image and corresponding SAED (inset) of representative rod-shaped structure. Scale bar in the inset is $2 \mathrm{~nm}^{-1}$. (b) HRTEM image of the margin of rod-shaped structures. (c) Low and (d) high magnification microtome TEM images of carbon coated anatase. Carbon layer is marked by red arrows. (e) Raman spectra of nanostructured anatase annealed under different atmospheres. (f) Thermogravimetric analysis of carbon coated anatase.
The carbon coating is marked by red arrows. The Raman spectra show two characteristic peaks at $1370 \mathrm{~cm}^{-1}$ and $1592 \mathrm{~cm}^{-1}$, which correspond to the D-band (disorder carbon) and G-band (graphitic carbon), respectively (Fig. 4e). The peaks at 397, 516 and $640 \mathrm{~cm}^{-1}$ are in accordance with the $\mathrm{B}_{1 \mathrm{~g}}, \mathrm{~A}_{1 \mathrm{~g}}$, and $\mathrm{E}_{\mathrm{g}}$ modes of the anatase phase. ${ }^{34}$ No characteristic carbon peaks are detected in $5-\mathrm{TiO}_{2}$. The carbon content was determined by thermogravimetric (TG) analysis (Fig. 4f). The exothermic peak at $134{ }^{\circ} \mathrm{C}$ is attributed to the evaporation of absorbed water, and the weight loss below $200{ }^{\circ} \mathrm{C}$ is about $2.5 \mathrm{wt} \%$. The exothermic peak at $427{ }^{\circ} \mathrm{C}$ is ascribed to the oxidation of carbon to carbon dioxide; the carbon content is about $13 \mathrm{wt} \%$. The content agrees with the calculated result of a model of the exposed surface coated by carbon (Fig. S9†).

The genetically engineered bacteria offer attractive advantages for the synthesis of nanostructured anatase (Fig. 5). The multifunctional protein $n \mathrm{R} 5$ displayed on the bacterial surface can interact with a titanium source electrostatically. The hydrolysis and condensation of precursors occur via hydrogen bond catalysis, leading to deposition of anatase nuclei on cell surfaces. The protein domains confine the growth and prohibit aggregation of anatase nanoparticles during heat treatment. The bacteria provide a three-dimensionally confined space as a template to maintain the rod structure composed of nanoparticles after calcination. The generation of coherent mesoporous structures may be from the decomposition of bioorganic compounds in bacteria. The bioorganic compounds serve as a carbon source through carbonization, so exposed nanoparticles surface coated by carbon can be achieved.

\section{Electrochemical performance of nanostructured anatase}

To evaluate the electrochemical characteristics of this unique structure, the products were fabricated into anodes for LIBs. Fig. 6a shows the cyclic voltammetry (CV) curves of the $n-\mathrm{TiO}_{2}(n$ $=1,3,5)$ and $5-\mathrm{TiO}_{2} / \mathrm{C}$ electrodes at a scanning rate of $0.1 \mathrm{mV}$ $\mathrm{s}^{-1}$. The two well-defined current peaks at about $1.75 \mathrm{~V}$ and 2.0

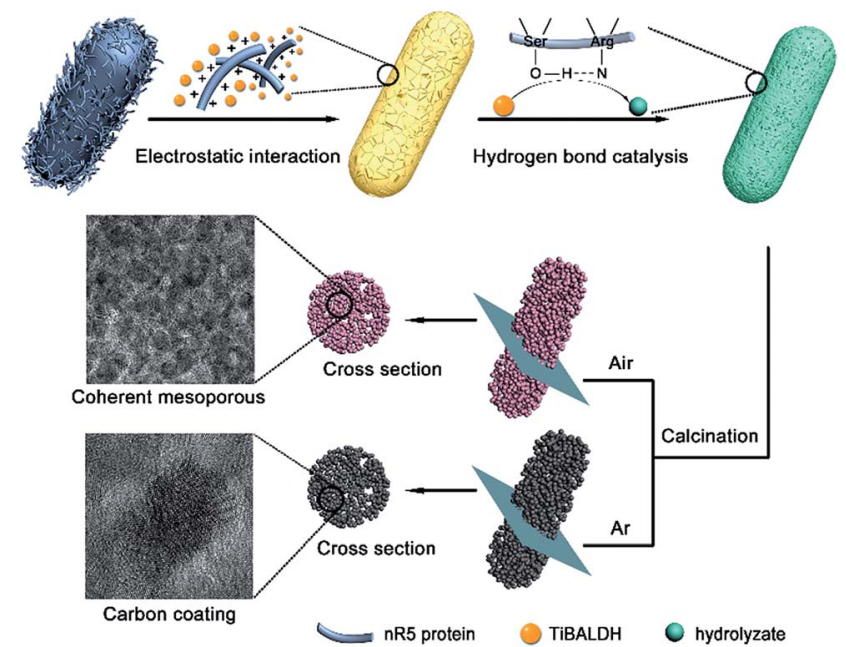

Fig. 5 Schematic of genetically engineered design strategy toward the confined space synthesis of nanostructured anatase. 
$\mathrm{V}$ are attributed respectively to the insertion and extraction of $\mathrm{Li}^{+}$ions in anatase phase. Fig. $6 \mathrm{~b}$ presents the charge-discharge profile voltage of electrodes at a current of $1 \mathrm{C}$, showing the 5$\mathrm{TiO}_{2} / \mathrm{C}$ electrode to have the highest specific capacity among all the electrode samples. The charge and discharge capacities of the $5-\mathrm{TiO}_{2} / \mathrm{C}$ electrode in the first cycle are $213 \mathrm{~mA} \mathrm{~h} \mathrm{~g}{ }^{-1}$ and 264 $\mathrm{mA} \mathrm{h} \mathrm{g}{ }^{-1}$, respectively (Fig. S10 $\dagger$ ). The 19.3\% irreversible capacity loss is ascribed mainly to the formation of a solid electrolyte interface (SEI) layer. ${ }^{35}$ Stable charge and discharge capacities were observed following cycling, with higher columbic efficiency and about $97 \%$ retention.

The cycling behavior of electrodes was investigated at a current of 1C (Fig. 6c). Clearly, all samples possessed superior capacity retention after 200 cycles, and $5-\mathrm{TiO}_{2} / \mathrm{C}$ showed the highest reversible capacity of $207 \mathrm{~mA} \mathrm{~h} \mathrm{~g}^{-1}$. Note that the specific capacity value was calculated using the $\mathrm{TiO}_{2} / \mathrm{C}$ composite. The reversible specific capacities of $5-\mathrm{TiO}_{2}, 3-\mathrm{TiO}_{2}$, and $1-\mathrm{TiO}_{2}$ after 200 cycles were determined to be 186, 174 and $154 \mathrm{~mA} \mathrm{~h} \mathrm{~g}^{-1}$, respectively. It was also determined that particle size substantially influences lithium storage capability, because smaller particles shorten the transport distance for $\mathrm{Li}^{+}$ions in the crystal phase and enhance surface $\mathrm{Li}$ storage, due to the higher specific surface area. ${ }^{36}$ At higher current rates of $5 \mathrm{C}$ and 10C, specific capacities delivered by $5-\mathrm{TiO}_{2} / \mathrm{C}$ electrodes were
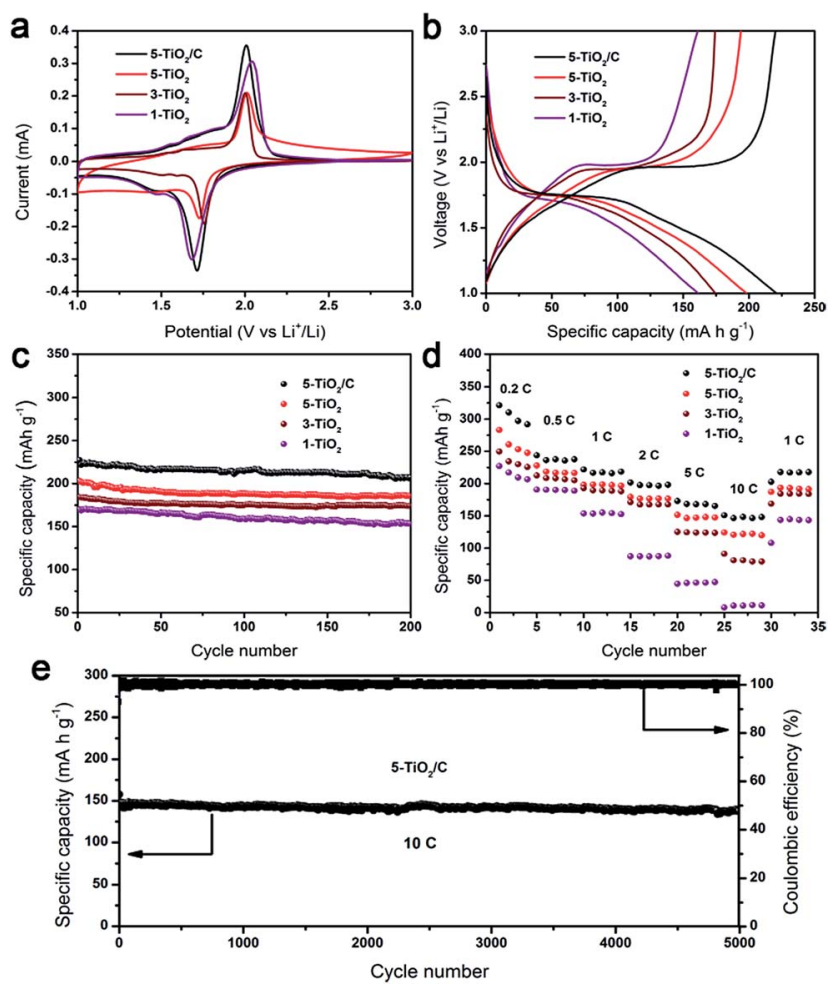

Fig. 6 Electrochemical performance of nanostructured anatase electrodes of $n-\mathrm{TiO}_{2}(n=1,3,5)$ and $5-\mathrm{TiO}_{2} / \mathrm{C}$. (a) Cyclic voltammetry curves of anatase electrodes at a scan rate of $0.1 \mathrm{mV} \mathrm{s}^{-1}$. (b) Chargedischarge voltage profiles of anatase electrodes at a current rate of $1 \mathrm{C}$. (c) Cycling performance of anatase electrodes at a current rate of $1 \mathrm{C}$. (d) Rate capability of anatase electrodes at various current rates. (e) Ultra-long life cycling performance of $5-\mathrm{TiO}_{2} / \mathrm{C}$ electrode at a high current rate of $10 \mathrm{C}$.
$165 \mathrm{~mA} \mathrm{~h} \mathrm{~g}^{-1}$ and $149 \mathrm{~mA} \mathrm{~h} \mathrm{~g}{ }^{-1}$, respectively, after 200 cycles (Fig. S11†).

To demonstrate structural stability during cycling, postmortem studies of $5-\mathrm{TiO}_{2}$ and $5-\mathrm{TiO}_{2} / \mathrm{C}$ electrodes after 200 charge-discharge cycles at the current rate of $1 \mathrm{C}$ were undertaken. The rod-shaped structures were found to have been retained well, and the nanoparticles remained uniformly coated on the surface (Fig. S12a-d $\dagger$ ), which is important to maintain structural stability and reversible capacity. The elemental mapping images of $5-\mathrm{TiO}_{2} / \mathrm{C}$ (Fig. S12e-h $\dagger$ ) also reveal a homogeneous distribution of $\mathrm{Ti}, \mathrm{O}$ and $\mathrm{C}$ on the rod-shaped anatase after 200 cycles, suggesting that this structure suppresses the aggregation of nanoparticles during cycling.

The rate capability of the two electrodes was examined at different rates of $0.2 \mathrm{C}, 0.5 \mathrm{C}, 1 \mathrm{C}, 2 \mathrm{C}, 5 \mathrm{C}$, and 10C (Fig. 6d). It was found that the specific capacities of $5-\mathrm{TiO}_{2} / \mathrm{C}$ (varied at 275,234 , 218, 199, 175 and $153 \mathrm{~mA} \mathrm{~h} \mathrm{~g}^{-1}$ ) were higher than those of $5-\mathrm{TiO}_{2}$ (varied at 227, 217, 188, 176, 153 and $123 \mathrm{~mA} \mathrm{~h} \mathrm{~g}^{-1}$ ) at each testing rate. Importantly, all electrodes recovered to the initial capacity of $1 \mathrm{C}$ after a high rate of $10 \mathrm{C}$, manifesting their high reversibility. However, compared to $5-\mathrm{TiO}_{2} / \mathrm{C}$ and $5-\mathrm{TiO}_{2}$ electrodes, the specific capacity of a commercial $5 \mathrm{~nm}$ powder electrode was the lowest, varying at 189, 178, 165, 156, 125 and $92 \mathrm{~mA}$ $\mathrm{h} \mathrm{g}^{-1}$ at each testing rate. Because the commercial $5 \mathrm{~nm}$ powder is prone to aggregation, it hinders $\mathrm{Li}^{+}$and electron transport and lowers the specific capacity (Fig. S13†). A similar phenomenon was seen when comparing commercial $15 \mathrm{~nm}$ powder and $1-\mathrm{TiO}_{2}$ electrodes. It is interesting that the $5-\mathrm{TiO}_{2} / \mathrm{C}$ electrode has an ultra-long cycling lifetime of 5000 cycles with an outstanding retention capacity of $149 \mathrm{~mA} \mathrm{~h} \mathrm{~g}^{-1}$ and almost no capacity loss at a rate of 10C (Fig. 6e). To the best of our knowledge, the electrochemical performance of the $5-\mathrm{TiO}_{2} / \mathrm{C}$ electrode is one of the best among the anatase $\mathrm{TiO}_{2}$ based materials (Table $\mathrm{S} 1 \dagger$ ).

To explore the superior electrochemical performance, electrochemical impedance spectroscopy (EIS) spectra were obtained to analyze the kinetic process of intercalation materials. Nyquist plots, containing semicircular and linear Warburg regions, of $5-\mathrm{TiO}_{2} / \mathrm{C}$ and $5-\mathrm{TiO}_{2}$ electrodes are presented in Fig. 7a. The semicircle in the middle frequency region is related to charge transfer resistance $\left(R_{\mathrm{ct}}\right)$, indicating $\mathrm{Li}^{+}$transfer across the interface between the electrolyte and electrode. ${ }^{37,38}$ The equivalent circuit (Fig. 7a inset) and fitting results (Table $\mathrm{S} 2 \dagger$ ) suggest that the $R_{\text {ct }}$ value of the $5-\mathrm{TiO}_{2} / \mathrm{C}$ electrode is much lower than that of the $5-\mathrm{TiO}_{2}$ electrode $(45.9 \Omega v s$. $69.6 \Omega)$. The reduction of $R_{\mathrm{ct}}$ suggests that the improved electrical conductivity is attributable to the interparticle contact with the carbon layers. ${ }^{39}$

In addition to electronic conductivity, the $\mathrm{Li}^{+}$apparent diffusion coefficient $\left(D_{\mathrm{Li}^{+}}\right)$of the $5-\mathrm{TiO}_{2} / \mathrm{C}$ electrode is also higher than that of $5-\mathrm{TiO}_{2}$ electrode. The value of $D_{\mathrm{Li}^{+}}$was calculated from the Nyquist plots at low frequency according to ref. 37

$$
D_{\mathrm{Li}^{+}}=R^{2} T^{2} / 2 A^{2} n^{4} F^{4} C^{2} \sigma^{2}
$$

where $R$ is the gas constant, $T$ is the absolute temperature, $A$ is the surface area of the electrode, $n$ is the number of electrons 

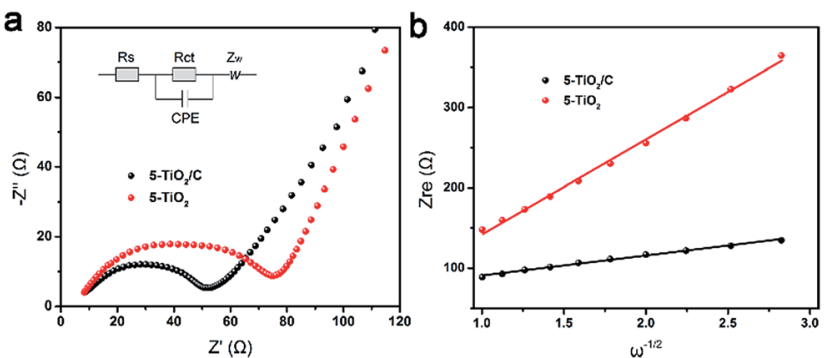

Fig. 7 Kinetic process analysis of anatase anode. (a) Nyquist plots of 5 $\mathrm{TiO}_{2} / \mathrm{C}$ and $5-\mathrm{TiO}_{2}$ electrodes. (b) Relationship between $Z_{\text {re }}$ plotted against $\omega^{-0.5}$.

per species reaction, $F$ is the Faraday constant, $C$ is the $\mathrm{Li}^{+}$ concentration and $\sigma$ is the Warburg factor associated with $Z_{\text {re }}$. The $\sigma$ is estimated by linear fitting of the plotted relationship between $Z_{\mathrm{re}}$ and $\omega^{-0.5}$ (Fig. 7b). The $D_{\mathrm{Li}^{+}}$of $5-\mathrm{TiO}_{2} / \mathrm{C}$ and $5-\mathrm{TiO}_{2}$ electrode is $3.85 \times 10^{-16} \mathrm{~cm}^{2} \mathrm{~s}^{-1}$ and $1.71 \times 10^{-17} \mathrm{~cm}^{2} \mathrm{~s}^{-1}$, respectively. Therefore, the $5-\mathrm{TiO}_{2} / \mathrm{C}$ electrode possesses both higher specific capacity and higher rate capability than the 5$\mathrm{TiO}_{2}$ electrode by taking advantage of faster $\mathrm{Li}^{+}$transport and lower charge transfer resistance.

We believe that the unique nanostructure of the anatase electrode is beneficial to the high capacity and enhanced stability for several reasons. First, nanosized particles reduce the lithium ion transport distance, which improves rate capability and cycle life compared to a bulk electrode. The unique structure assembled by nanoparticles can efficiently avoid the stacking or aggregation of nanoparticles. Second, the mesoporous structure can tolerate the volume change during lithium ion insertion and extraction, provides more channels for lithium ion diffusion and prevents the collapse of the electrode. The $5-\mathrm{TiO}_{2} / \mathrm{C}$ material not only possesses the above structural characteristics, but also has an additional carbon coating on the nanoparticle surfaces, which improves the intrinsically poor conductivity of anatase and limits the amount of SEI. ${ }^{40}$ Therefore, a bi-continuous 5 - $\mathrm{TiO}_{2} / \mathrm{C}$ electrode can facilitate rapid lithium ion and electron diffusion, while exhibiting higher capacity and better rate capability than those of the $5-\mathrm{TiO}_{2}$ electrode.

\section{Conclusions}

The cell surface display technology consolidates catalytically active proteins in a three-dimensionally confined space. It was adopted to direct the synthesis of nanostructured anatase. Briefly, an artificial protein, 5R5, was displayed on the surface of $E$. coli through the function of INP. The positively charged 5R5 interacted with a negatively charged titanium source through electrostatic interaction. The hydrogen bonding interaction catalysed the hydrolysis and condensation of titanium dioxide precursors on the $E$. coli cell surface. Upon heat treatment, $E$. coli cells acted as framework, to allow the transformation of titanium dioxide precursors into well-assembled $5 \mathrm{~nm}$ anatase $\mathrm{TiO}_{2}$ nanoparticles. Carbon coating on the assembled anatase $\mathrm{TiO}_{2}$ nanoparticles was achieved by annealing in an inert atmosphere. Furthermore, the size of nanoparticles was controlled by changing the number of tandem repeated units in R5 segments. As an anode electrode, this unique nanostructured anode - with nanosized anatase crystals, mesoporous structure and carbon coating - is superior in specific capacity, rate capability and cycling stability compared to conventional electrodes.

\section{Acknowledgements}

This work was financially supported by the National Natural Science Foundation of China (51521001) and the Ministry of Science and Technology of the People's Republic of China (2015DFR50650). We acknowledge Miss Ting-ting Luo (Center for Materials Re-search and Analysis, Wuhan University of Technology) for her help in HRTEM analysis. We are grateful to Bi-Chao Xu of the Core Facility and Technical Support, Wuhan Institute of Virology for her technical support in sample embedding.

\section{Notes and references}

1 C. Sanchez, H. Arribart and M. M. G. Guille, Nat. Mater., 2005, 4, 277-288.

2 J. J. Xie, H. Xie, B. L. Su, Y. B. Cheng, X. D. Du, H. Zeng, M. H. Wang, W. M. Wang, H. Wang and Z. Y. Fu, Angew. Chem., Int. Ed., 2016, 55, 3031-3035.

3 H. Ping, H. Xie, B. L. Su, Y. B. Cheng, W. M. Wang, H. Wang, Y. C. Wang, J. Y. Zhang, F. Zhang and Z. Y. Fu, J. Mater. Chem. B, 2015, 3, 4496-4502.

4 J. Mahamid, B. Aichmayer, E. Shimoni, R. Ziblat, C. H. Li, S. Siegel, O. Paris, P. Fratzl, S. Weiner and L. Addadi, Proc. Natl. Acad. Sci. U. S. A., 2010, 107, 6316-6321.

5 L. B. Gower, Chem. Rev., 2008, 108, 4551-4627.

6 C. J. Stephens, S. F. Ladden, F. C. Meldrum and H. K. Christenson, Adv. Funct. Mater., 2010, 20, 2108-2115.

7 R. L. Brutchey and D. E. Morse, Chem. Rev., 2008, 108, 49154934.

8 N. Kroger, M. B. Dickerson, G. Ahmad, Y. Cai, M. S. Haluska, K. H. Sandhage, N. Poulsen and V. C. Sheppard, Angew. Chem., Int. Ed., 2006, 45, 7239-7243.

9 Y. Y. Kim, N. B. J. Hetherington, E. H. Noel, R. Kroger, J. M. Charnock, H. K. Christenson and F. C. Meldrum, Angew. Chem., Int. Ed., 2011, 50, 12572-12577.

10 A. S. Schenk, E. J. Albarracin, Y. Y. Kim, J. Ihli and F. C. Meldrum, Chem. Commun., 2014, 50, 4729-4732.

11 S. Bolisetty, J. Adamcik, J. Heier and R. Mezzenga, Adv. Funct. Mater., 2012, 22, 3424-3428.

12 P. Y. Chen, X. N. Dang, M. T. Klug, J. F. Qi, N. M. D. Courchesne, F. J. Burpo, N. Fang, P. T. Hammond and A. M. Belcher, ACS Nano, 2013, 7, 6563-6574.

13 X. N. Dang, H. J. Yi, M. H. Ham, J. F. Qi, D. S. Yun, R. Ladewski, M. S. Strano, P. T. Hammond and A. M. Belcher, Nat. Nanotechnol., 2011, 6, 377-384.

14 Y. J. Lee, H. Yi, W. J. Kim, K. Kang, D. S. Yun, M. S. Strano, G. Ceder and A. M. Belcher, Science, 2009, 324, 1051-1055. 
15 E. Kharlampieva, T. Tsukruk, J. M. Slocik, H. Ko, N. Poulsen, R. R. Naik, N. Kroger and V. V. Tsukruk, Adv. Mater., 2008, 20, 3274-3279.

16 R. Andre, M. N. Tahir, H. C. C. Schroder, W. E. G. Muller and W. Tremel, Chem. Mater., 2011, 23, 5358-5365.

17 C. Rosant, B. Avalle, D. Larcher, L. Dupont, A. Friboulet and J. M. Tarascon, Energy Environ. Sci., 2012, 5, 9936-9943.

18 W. E. G. Muller, S. Engel, X. H. Wang, S. E. Wolf, W. G. Tremel, N. L. Thakur, A. Krasko, M. Divekar and H. C. Schroder, Biomaterials, 2008, 29, 771-779.

19 P. Curnow, P. H. Bessette, D. Kisailus, M. M. Murr, P. S. Daugherty and D. E. Morse, J. Am. Chem. Soc., 2005, 127, 15749-15755.

20 P. Curnow, D. Kisailus and D. E. Morse, Angew. Chem., Int. Ed., 2006, 45, 613-616.

21 J. S. Chen, Y. L. Tan, C. M. Li, Y. L. Cheah, D. Y. Luan, S. Madhavi, F. Y. C. Boey, L. A. Archer and X. W. Lou, J. Am. Chem. Soc., 2010, 132, 6124-6130.

22 W. Q. Wu, Y. F. Xu, H. S. Rao, C. Y. Su and D. B. Kuang, J. Am. Chem. Soc., 2014, 136, 6437-6445.

23 Y. X. Tang, Y. Y. Zhang, J. Y. Deng, J. Q. Wei, H. L. Tam, B. K. Chandran, Z. L. Dong, Z. Chen and X. D. Chen, Adv. Mater., 2014, 26, 6111-6118.

24 Y. X. Tang, Y. Y. Zhang, W. L. Li, B. Ma and X. D. Chen, Chem. Soc. Rev., 2015, 44, 5926-5940.

25 J. Y. Shin, D. Samuelis and J. Maier, Adv. Funct. Mater., 2011, 21, 3464-3472.

26 S. H. Yu, D. J. Lee, M. Park, S. G. Kwon, H. S. Lee, A. Jin, K. S. Lee, J. E. Lee, M. H. Oh, K. Kang, Y. E. Sung and T. Hyeon, J. Am. Chem. Soc., 2015, 137, 11954-11961.

27 S. H. Yang, E. H. Ko and I. S. Choi, Langmuir, 2012, 28, 21512155.
28 S. Y. Lee, J. H. Choi and Z. H. Xu, Trends Biotechnol., 2003, 21, 45-52.

29 D. Kisailus, Q. Truong, Y. Amemiya, J. C. Weaver and D. E. Morse, Proc. Natl. Acad. Sci. U. S. A., 2006, 103, 56525657.

30 R. L. Brutchey, E. S. Yoo and D. E. Morse, J. Am. Chem. Soc., 2006, 128, 10288-10294.

31 E. Kharlampieva, C. M. Jung, V. Kozlovskaya and V. V. Tsukruk, J. Mater. Chem., 2010, 20, 5242-5250.

32 E. Kharlampieva, J. M. Slocik, S. Singamaneni, N. Poulsen, N. Kroger, R. R. Naik and V. V. Tsukruk, Adv. Funct. Mater., 2009, 19, 2303-2311.

33 H. Q. Li and H. S. Zhou, Chem. Commun., 2012, 48, 12011217.

34 Z. S. Hong, M. D. Wei, T. B. Lan, L. L. Jiang and G. Z. Cao, Energy Environ. Sci., 2012, 5, 5408-5413.

35 S. H. Yu, D. E. Conte, S. Baek, D. C. Lee, S. K. Park, K. J. Lee, Y. Piao, Y. E. Sung and N. Pinna, Adv. Funct. Mater., 2013, 23, 4293-4305.

36 R. Mo, Z. Lei, K. Sun and D. Rooney, Adv. Mater., 2014, 26, 2084-2088.

37 Y. X. Tang, Y. Y. Zhang, X. H. Rui, D. P. Qi, Y. F. Luo, W. R. Leow, S. Chen, J. Guo, J. Q. Wei, W. L. Li, J. Y. Deng, Y. K. Lai, B. Ma and X. D. Chen, Adv. Mater., 2016, 28, 1567-1576.

38 Y. X. Tang, Y. Y. Zhang, J. Y. Deng, D. P. Qi, W. R. Leow, J. Q. Wei, S. Y. Yin, Z. L. Dong, R. Yazami, Z. Chen and X. D. Chen, Angew. Chem., Int. Ed., 2014, 53, 13488-13492.

39 Y. R. Zhong, M. Yang, X. L. Zhou, Y. T. Luo, J. P. Wei and Z. Zhou, Adv. Mater., 2015, 27, 806-812.

40 N. Liu, Z. D. Lu, J. Zhao, M. T. McDowell, H. W. Lee, W. T. Zhao and Y. Cui, Nat. Nanotechnol., 2014, 9, 187-192. 